\title{
Uncommon Tissue Defects of Upper Extremities: Bacillus Antracis
}

\author{
Osman Akdag1,2, Gokce Yildiran1,2, Mustafa Sutcu3 ${ }^{3}$, Mehtap Karamese ${ }^{1,2}$, Zekeriya Tosun 1,2 \\ ${ }^{1}$ Plastic, Reconstructive and Aesthetic Surgery Department, Medical Faculty, Selcuk University, Konya, Turkey \\ ${ }^{2}$ Plastic Surgery Department of University Hospital, Selcuk University Alaaadin Keykubat Campus, Konya, Turkey \\ ${ }^{3}$ Plastic, Reconstructive and Aesthetic Surgery Department, Medical Faculty, Medipol University, Istanbul, \\ Turkey \\ Email: oakdag@gmail.com,ggokceunal@gmail.com,msutcu@gmail.com, mehtapef@yahoo.com, \\ drtosunz@gmail.com
}

Received 20 March 2016; accepted 16 April 2016; published 19 April 2016

Copyright (C) 2016 by authors and Scientific Research Publishing Inc.

This work is licensed under the Creative Commons Attribution International License (CC BY).

http://creativecommons.org/licenses/by/4.0/

c) (i) Open Access

\begin{abstract}
Introduction: Anthrax is a zoonotic disease caused by Bacillus anthracis spores. Cutaneous form is the most common and the least fatal form of the disease, however the disease is uncommon in Europe and U.S. and the reports in the literature are mostly case reports for upper extremity. Case Series: 7 patients, who were treated between 1999 and 2015 in our clinic with the diagnosis of cutaneous anthrax in their upper extremity, were included to our study. 3 patients applied directly to plastic surgery, others were consulted from the infectious disease clinics. Reconstructions were done with skin grafts or secondarily. Discussion: Anthrax causes cutaneous, gastrointestinal and inhalation forms of the disease. Despite being very rare in Europe and US, in Turkey there are many reported anthrax cases. However, cutaneous anthrax of upper extremity is reported rarely in the literature. Painless papule and vesicles are well defined as clinical findings. In anthrax, the excision of skin lesions or biopsies is contraindicated because of the risk of systemic spread. Conclusion: Despite cutaneous anthrax of the hand and upper extremity is very rare, the diagnosis is easy because of the typical presentation and history. Once the definitive diagnosis is set, the treatment is effortless with the antibiotherapy and first steps of the reconstruction ladder.
\end{abstract}

\section{Keywords}

Anthrax, Cutaneous Anthrax, Hand, Upper Extremity

\section{Introduction}

Anthrax is a zoonotic disease caused by Bacillus anthracis spores. B. anthracis is gram positive, aerobic and 
spore-forming rod [1] [2]. It causes cutaneous, gastrointestinal and inhalation forms of the disease in human who had an infected animal contact. Cutaneous form is the most common and the least fatal form of the disease and it emerges due to the anthrax spores that enter the skin from scratches and wounds. It is common in developing countries, uncommon in Europe and U.S. and the reports in the literature are mostly case reports [3] [4]. It is aimed to present our anthrax series and the disease's clinical presentations.

\section{Case Series}

7 patients, who were treated between 1999 and 2015 in our clinic with the diagnosis of cutaneous anthrax in their upper extremity were included to our study and evaluated retrospectively. All patients got the diagnosis by bacteriological examination. Patients were classified according to their age, sex, profession, history, lesion localization and treatment (Table 1). 3 patients applied directly to plastic surgery, others were consulted from the infectious disease clinics. 1 female and 6 male patients' mean age was 44.2. 4 patients were professional butchers and other 3 patients had an anamnesis of animal contact. 4 patients' defects were reconstructed with split thickness skin graft (STSG). 2 patients' defects were reconstructed with full thickness skin graft (FTSG). 2 patients' wounds were healed secondarily. Ethics approval for the study was obtained from the local ethics committee.

Case 1:

51-year-old male, farmer patient was admitted to plastic surgery clinics directly. He had skin necrosis over the dorsum of the hand (Figure 1). After the ciprofloxacin treatment, had started by infection diseases, surgical debridement was applied and the defect was reconstructed with split thickness skin graft (Figure 2 and Figure 3).

\begin{tabular}{|c|c|c|c|c|c|c|c|}
\hline & Age & Sex & $\begin{array}{c}\text { Profession \& } \\
\text { History }\end{array}$ & Localization & $\begin{array}{c}\text { Clinical } \\
\text { presentation }\end{array}$ & $\begin{array}{c}\text { Surgical } \\
\text { Treatment }\end{array}$ & Outcome \\
\hline Case 1 & 51 & Male & $\begin{array}{l}\text { Farmer \& animal } \\
\text { contact }\end{array}$ & Hand dorsum & Eschar & STSG & Recovered \\
\hline Case 2 & 33 & Male & Butcher & Forearm & Eschar & STSG & Recovered \\
\hline Case 3 & 65 & Female & Animal contact & Thumb & Vesicle & Secondary intention & Recovered \\
\hline Case 4 & 45 & Male & Butcher & Forearm & Eschar & STSG & Recovered \\
\hline Case 5 & 45 & Male & Butcher & Hand dorsum & Papule \& Eschar & Secondary intention & Recovered \\
\hline Case 6 & 30 & Male & Butcher & Hand dorsum & Eschar & FTSG & Recovered \\
\hline Case 7 & 41 & Male & $\begin{array}{l}\text { Farmer \& animal } \\
\text { contact }\end{array}$ & Forearm & Eschar & FTSG & Recovered \\
\hline
\end{tabular}

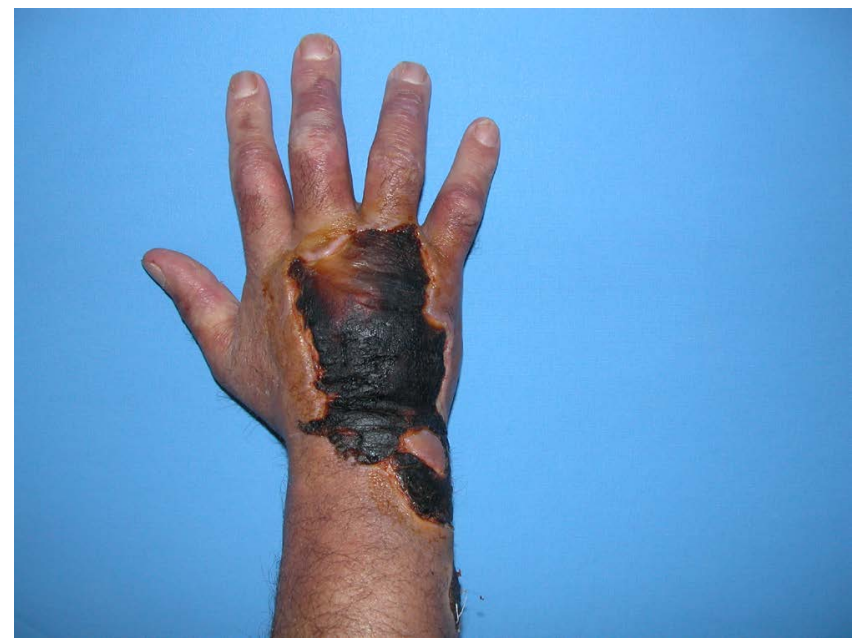

Figure 1. Cutaneous anthrax of hand, the escar presentation of anthrax. 


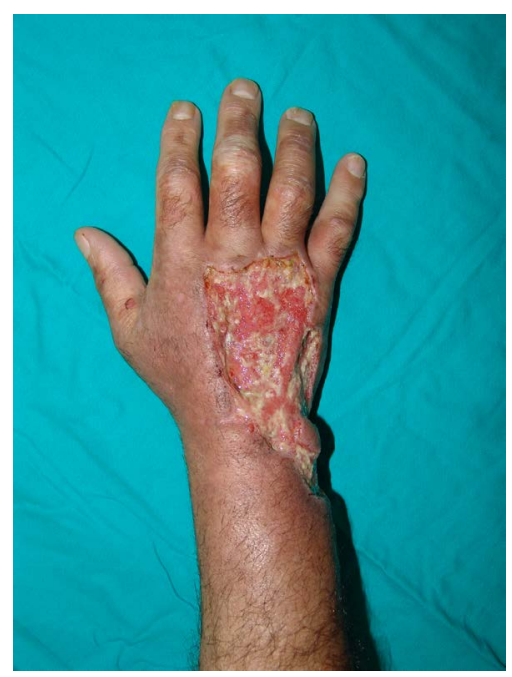

Figure 2. After debridement, intraoperative view.

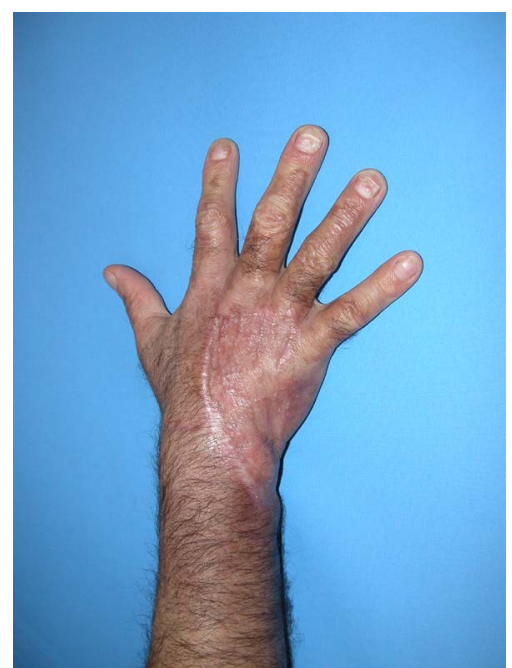

Figure 3. Second month view of anthrax, reconstructed with STSG.

Case 2:

33-year-old male, butcher patient was referred to our clinic from infection diseases, after he had the suitable antibiotherapy for anthrax (Figure 4). Necrotic tissues of the forearm were debrided surgically and the defect was reconstructed with split thickness skin graft (Figure 5).

Case 3:

65-year-old female patient, who had an animal contact, was admitted to our clinics with a bullous formation of her thumb (Figure 6). Bacteriological examinations were studied in order to confirm the anthrax suspicion. After the antibiotherapy, the wound was healed by secondary intention (Figure 7).

\section{Discussion}

Anthrax was described by Heinrich Hermann Robert Koch in 1877. Anthrax causes cutaneous, gastrointestinal and inhalation forms of the disease. Despite being very rare in Europe and US, in Turkey there are many reported anthrax cases [5]. However, cutaneous anthrax of upper extremity is reported rarely in the literature. In our case series, 7 patients with cutaneous anthrax with their upper extremity were presented. Despite painless pruritic papule and animal exposure history is very typical for the diagnosis, the diagnosis of cutaneous anthrax requires suspicion. Definitive diagnosis is set by gram stain and microbiological analysis of lesion [6]. Painless 


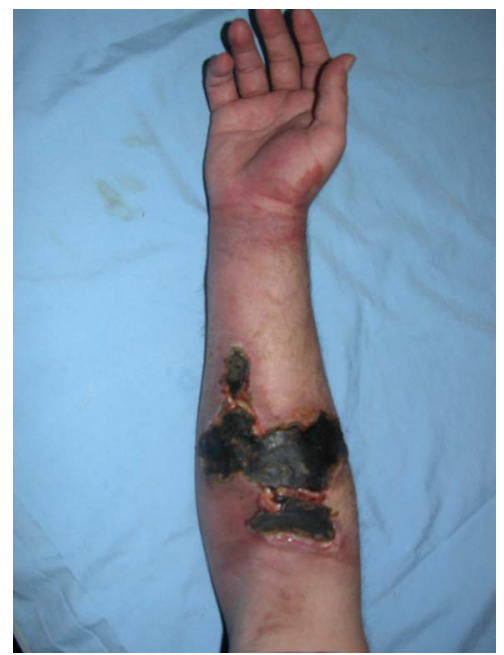

Figure 4. Forearm anthrax, before debridement of necrotic tissues.

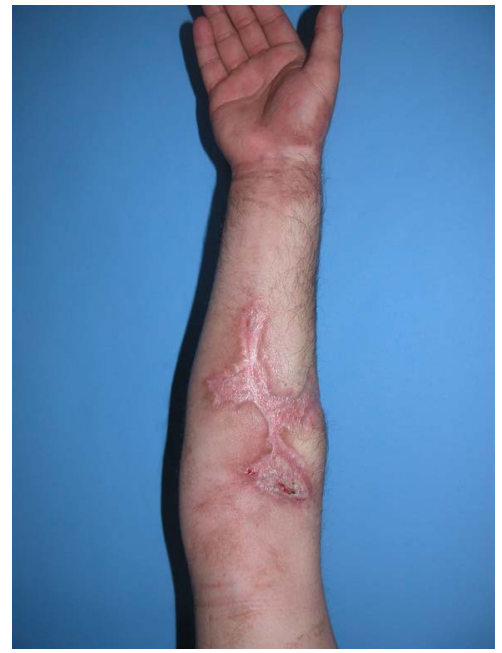

Figure 5. STSG closure, the view of recovered anthrax infection after reconstruction.

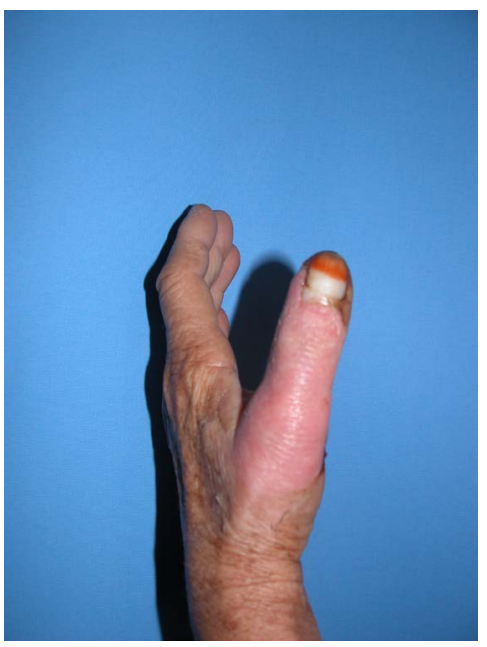

Figure 6. Bullous formation of cutaneous anthrax. 


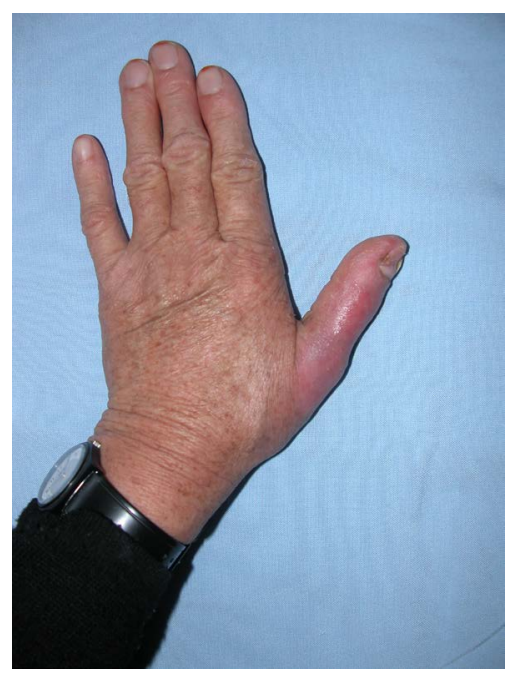

Figure 7. After antibiotherapy, recovered view with secondary intention.

papule and vesicles are well defined as clinical findings. Coban et al. were presented a case with eschar tissue on the dorsum of the hand. In our patients; papule, vesicle and eschar formations were the clinical presentations. The most common presentation type was eschar tissue in our series.

Eschar tissue with edema is emerged later than the papule lesion because of the bacterial toxin. The lesions are varied from $1 \mathrm{~cm}$ in diameter like an insect bite, to such big lesions that need a fasciotomy for the compartment syndrome. In the eschar period, a possible compartment syndrome should be noted. After the eschar tissue settled, it begins to divide, dry and loosen.

Because anthrax is mostly seen in endemic regions, many patients were recognized and treated before the eschar period [7]. However most of our patients were presented with eschar tissue. We contribute this to the undeveloped awareness of patients about anthrax in Central Anatolia region because of not being an endemic region like Eastern Anatolia [7].

However the presentation is typical, combination with the patient history is crucial. In our series, 4 patients were professional butchers, 2 patients were farmer and they had animal contact and also 1 patient had an animal contact.

In anthrax, the excision of skin lesions or biopsies is contraindicated because of the risk of systemic spread [8]. For this reason, surgery is the preferred method of definitive cure only after the after antibiotic treatment. Also, when a patient is presented with eschar tissue; it should be noted that often there is a viable tissue under the eschar, so that the escharatomy shouldn't be done very aggressively even if it seems very destructive.

Penicillin, ciprofloxacin and doxycycline are mainly used for the antibiotherapy [2]. Our patients were treated in line with the infectious disease's proposals either with penicillin or ciprofloxacin. Antibiotherapy reduces the mortality from $20 \%$ to $1 \%$.

In the literature, hand anthrax's most common presentation region is the hand dorsum. Forearm and finger regions are rarely reported. Our 3 of 7 patients were suffered from the hand dorsal region, 3 of them were affected from the forearm and 1 patient had a vesicle in her thumb. Despite being related with the animal contact, the grabbing side of the hand-the palm region—affected less commonly. Dogan et al. were explained this issue with the palmar skin thickness and eccrine land protection of palmar side [9]. In our cases there weren't any palmar anthrax.

Tissue defects secondary to trauma, tumor and burn are frequently encountered in plastic surgery clinics. Yet, anthrax rarely causes tissue defects and it mostly heals with antibiotherapy spontaneously [8]. Some cases may need wide debridement due to the wide eschar tissue as in our patients (Patient 1, 2). If anthrax causes skin defect, after antibiotherapy ad surgical debridement, the reconstruction of the tissue defect doesn't differ from an ordinary tissue defect. Surgeon should be considered the reconstruction ladder to reconstruct an anthrax defect. Leaving the wound heal by the secondary healing, split thickness skin grafts, full thickness skin grafts and skin flaps are the treatment options in anthrax. Our patients' defects were reconstructed with secondary intention, 
split thickness skin grafts and full thickness skin grafts.

Despite cutaneous anthrax of the hand and upper extremity is very rare, the diagnosis is easy because of the typical presentation and history. Once the definitive diagnosis is set, the treatment is effortless with the antibiotherapy and first steps of the reconstruction ladder.

\section{References}

[1] Demirdag, K., Ozden, M., Saral, Y., Kalkan, A., Kilic, S.S. and Ozdarendeli, A. (2003) Cutaneous Anthrax in Adults: A Review of 25 Cases in the Eastern Anatolian Region of Turkey. Infection, 31, 327-330.

[2] Tekin, R., Sula, B., Devec1, O., Tekin, A., Bozkurt, F., Ucmak, D., Kaya, Ş., Bekcibasi, M., Erkan, M.E., Ayaz, C. and Hosoglu, S. (2015) Cutaneous Anthrax in Southeast Anatolia of Turkey. Cutaneous and Ocular Toxicology, 34, 7-11. http://dx.doi.org/10.3109/15569527.2014.880844

[3] Coban, Y.K., Balik, O. and Boran, C. (2002) Cutaneous Anthrax of the Hand and Its Reconstruction with a ReverseFlow Radial Forearm Flap. Annals of Plastic Surgery, 49, 109-111. http://dx.doi.org/10.1097/00000637-200207000-00017

[4] Oncül, O., Ozsoy, M.F., Gul, H.C., Koçak, N., Cavuslu, S. and Pahsa, A. (2002) Cutaneous Anthrax in Turkey: A Review of 32 Cases. Scandinavian Journal of Infectious Diseases, 34, 413-416. http://dx.doi.org/10.1080/00365540110080610

[5] Yucel, O.T. (2005) Cutaneous Anthrax. Otolaryngology—Head and Neck Surgery, 133, 462-463. http://dx.doi.org/10.1016/j.otohns.2005.05.048

[6] Denk, A., Tartar, A.S., Ozden, M., Demir, B. and Akbulut, A. (2015) Cutaneous Anthrax: Evaluation of 28 Cases in the Eastern Anatolian Region of Turkey. Cutaneous and Ocular Toxicology, 21, 1-4. http://dx.doi.org/10.3109/15569527.2015.1067818

[7] Aslan, G. and Terzioğlu, A. (1998) Surgical Management of Cutaneous Anthrax. Annals of Plastic Surgery, 41, 468470. http://dx.doi.org/10.1097/00000637-199811000-00003

[8] Godyn, J.J., Reyes, L., Siderits, R. and Hazra, A. (2005) Cutaneous Anthrax: Conservative or Surgical Treatment? Advances in Skin \& Wound Care, 18, 146-50. Review. Erratum in: Adv Skin Wound Care, 18, 228. http://dx.doi.org/10.1097/00129334-200504000-00012

[9] Dogan, T., Unzile, B. and Gurcan, A. (2004) Cutaneous Anthrax of the Hand. Indian Journal of Plastic Surgery, 37, 131-133. 